\title{
Improvisation in teaching physics concepts: Teachers' experiences and perceptions
}

Kira, Ernest

Sokoine University of Agriculture, Tanzania (klesiani@yahoo.com)

Nchunga, Ayubu

Korogwe Teachers College, Tanzania (ayubnchunga@yahoo.com)

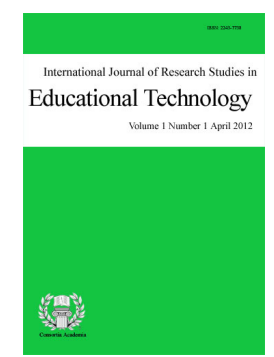

ISSN: $2243-7738$ Online ISSN: 2243-7746

\begin{abstract}
The purpose of this study was to design and assess the use of Improvised Instructional Materials (IIM) in teaching physics lessons in Tanga region whereby two Community Secondary Schools (CSS) from Korogwe district and the city of Tanga were selected for implementation of IIM. A total of eight teachers were selected from the sampled schools where by each school provided two physics teachers. The researchers planned and prepared the materials in advance before coaching the teachers on how to implement them. Teachers' ability to execute student centered teaching approaches was assessed before and after coaching. It was found out that the use of improvised instructional materials to run practical lessons has refined and broadens teachers' knowledge on designing and the use of such local materials to carry out physics experiments in CSS.
\end{abstract}

Keywords: improvisation; physics; teachers; teaching; experiences; perceptions 


\section{Improvisation in teaching physics concepts: Teachers' experiences and perceptions}

\section{Introduction}

In 1990s, the government of Tanzania introduced education reforms which were implemented through the 'Sector Wide Approach' adopted in the Education Sector Development Programme (ESDP) (MoEC, 2004). Within the context of ESDP and Secondary Education Master Plan (SEMP) the Secondary Education Development Plan (SEDP) was developed. The overall goal of SEDP is to increase the proportion of Tanzania youths who can access and complete secondary education at lower and upper levels with acceptable learning achievements. According to the findings, in 1997 Tanzania had only 350 government secondary schools but by 2006, the number of government schools had risen to 1,690 (Ministry of Education and Vocational Training, 2008). The driving factor behind this dramatic increase was the general freeing-up policies and structures in Tanzania from the early 1990s, exemplified in the option for communities to build their own secondary schools and have them staffed and operated by the government (MoEVT, 2007).

Apart from increasing enrolment other goals of SEDP were (i) to build laboratories and libraries; (ii) to provide laboratory equipments, chemicals and other incentives and (iii) to train adequate number of science teachers (MoEC, 2004). Despite the presence of classrooms and increase of students' enrolment, the promise of SEDP to improve science teaching and learning in the Community Secondary Schools is still facing a number of challenges such as inadequacy of quality and quantity of science teachers, teaching and learning materials, both laboratory rooms and equipments, and other consumable materials (Kira \& Mahumbwe, 2015; Mafumiko, 2008). As a consequence, less number of students gets interested with physical sciences; for example, data from Tanzania National Examination Council 'NECTA indicates that, there has been a decline of interest on physics subject in O-level secondary schools as featured out by a massive dropout of learners (URT, 2009). On the other hand even those students opting for physics subject are not performing well in their National Examinations.

Observations done by Lujara et al. (2006) reveal that performance in most science subjects is poor, but that of mathematics and physics were comparatively poorer. The problem is compounded by the lack of qualified physics teachers. The study by Lutege (2008) on implementation of Problem-Solving methods in Science education revealed that, teacher-centred method is highly used in A-level physics teaching. Other methods such as the project method, demonstration, group discussion, practical work lessons were given little attention. Chonjo, Osaki, Possi, and Mrutu, (1996); Kira, Komba, Kafanabo, and Tilya (2013) from their situational analysis investigation on science teaching in secondary school found that, most teachers had inadequate practical skills and continued to use the lecture method which promoted less understanding. Therefore there is a need for researchers to support science teachers to execute their lessons

\subsection{Aim of the Study}

In this study the researcher intended to improvise locally available materials to conduct practical lessons for selected O-level physics concepts. Therefore, the researchers designed instructional materials by using local resources and were then used by teachers to conduct practical lessons in selected Community Secondary Schools (CSS). Then, the researchers determined teachers' perceptions. Significance of this study lies in the fact that if teachers can simplify their work through this improvisation it will raise students' achievement because research shows that stress towards a difficult science task lowers the self-efficacy of the students (Montebon, 2016)

\section{Literature Review}

The teaching approach that a teacher adopts and the available materials he/she teaches with are factors that may affect students achievement (Mills, 1991; Olufunke, 2012) as many teachers belief that hand-on experience 
is the heart of physics learning (Chinyere, 2014). This perception is backed by prior research that conceptual understanding is only accomplished through learning that promotes conceptual change (Piaget, 1985; Vosnadou, 1994; Zacharia, 2007) also noted that, in order to foster conceptual change, students have to be confronted with discrepant events that contradict their conceptions and invoke a disequilibrium or cognitive conflict that positions students in a state of reflection and resolution.

Conceptual change for abstract content may be difficult without careful selection of instructional materials. For instance it has been observed that teaching of physics in schools has not been encouraging due to the abstract nature of the subject that is why the use of instructional materials is needed to facilitate students' learning of physics (Aina, 2013). Instructional materials are used to supplement verbal explanation of concepts or any description so that the lesson could be real to the students. These instructional materials are categorized into audio visual, audio and visual. These are materials that when teacher used them can appeal to student both sight and hearing (Aina, 2013). Kola (2007) reported that instructional media or materials increase students' activeness and participation. It was from this context that physics laboratory becomes inevitable as Akanbi (2003) associated with students performance that laboratory apparatus is the 'heart' of science learning and where not found or insufficient, students' academic achievement will be very low or poor, this was the argument that inadequate laboratory equipment and facilities lead to students' poor performance in physics.

Some scholars think that the importance of traditional laboratory teaching involving practical experimentation and hands on work has in no way decreased as a result of computerized simulation experiments though considerable pedagogical advantage may also be gained by the integration of ICT tools used in teaching science and technology particularly by integrating virtual laboratories (Crispen et al., 2010). There are many experiments very difficult to carry out in the laboratory due to their nature, such experiment could be simulated. Chain reaction and radioactive decay in nuclear Physics cannot be easily carried out in classroom situation; students can still learn these topics by simulation and it will be real to them. Also, microcomputer can be used to acquire data from thermistor, photodiodes and pressure transistors (Wilson \& Redish, 1989). But In Tanzania there is problem of electric power supply, because of this many electronic experiments in Physics that requires the use of electricity is not always reliable while in most of the rural places there is no power supply at all.

One would expect the teacher, who is the facilitator in the teaching-learning process, to improvise for materials where they are not available or are insufficient. But the attitudes of the teachers towards improvisation of teaching materials are negative. Many of the teachers are not aware of the improvisation method in teaching (Njoku 2000). Those that are aware of the use of local equipment and materials in teaching are hindered by a number of factors such as laziness on their part, lack of funds, time constraints, and many others (Jegede, \& Adedayo, 2013).

Balogun (2002) categorized constraints against the successful improvisation of science equipment in to two main forms. These are the technical and the human factors. While the technical factors relate to the question of degree of accuracy and precision that is possible with the improvised equipment, the human factor relates to the teachers' skill in developing the resources while providing the appropriate learning experience to the learners. The role of the human factors can be associated with the observation that the perceptions of teachers teaching physics raise students' performance (Adedayo, 2010; Adeyemo, 2011; Chinyere, 2014; Hong \& Vargas, 2016). But Omotayo (2009) and Nwagbo (1995) reported lack of adequate professional training as a major problem militating against the effective use of local resources for Science teaching.

If improvisation aims at enhancing student-centered teaching approach rather than teacher-centered one, there is a challenge that despite the fact that the value of the student-centered approach is widely acknowledged among educators in several parts of the world still majority of teachers and institutions are nevertheless not adhering to it (Jokolo, 2004). Teacher centered approach is sometimes viewed as relatively efficient since it allows educators to teach many students within a rather short period of time. Unfortunately, in most situations such conditions may promote a "surface" rather than "deep" level of understanding and orient students 
Kira, E., \& Nchunga, A.

towards performing only at the minimal level required to obtain a good grade in the course (Biggs, 1999).

This implies that, for teachers to be able to buy the concept of improvisation in education they first need to change their role as professionals, to develop competence programs, to adapt their lectures to include interactions with the class, to consider students' prior knowledge and background (impact of cultures), as well as orient and guide students in their learning process (Gardner, 2012). In other words, teachers will need to accept that the relationship between teaching and learning is now different (Tagg \& Barr, 1995). This is the reason why Isola (2010) then stressed the need for a definite well planned training program of improvisation for teachers. He suggested regular meaningful workshop on improvisation technique for Science teachers to improve and up-to-date their competence.

\section{Methodology}

Cross-sectional survey design was used to locate community secondary schools to take part in the study. These schools were selected on the basis of criteria of limited laboratory resources, having physics teacher(s) as well as form three class students opting physics subject. In order to meet the main aim of the study an action research design was employed. Action research is an approach in which the researcher and a client collaborate in the diagnosis of the problem and in development of solution based on the diagnosis (Bryman, 2001). The main philosophy of the IIM is to encourage teachers to apply improvisation approach to design and use available local materials to run practical lessons in under resourced schools

The study is structured by an intervention, development of improvised instructional materials followed by reflective sessions and trial of the instructional materials. The following activities were carried out in the selected Community Secondary Schools:

$>$ Interviews were carried out on teachers to assess the way practical lessons were organized and facilitated under the limited laboratory resources.

$>\quad$ The researchers designed the instructional materials (IIM) using local materials collected around the school premises. The IIM comprises local resources such as plastic bottles, pieces of wood, stones with weight 50 and 100 grams, used syringes, bicycle ball bearings, water and rubber bands.

$>$ Teachers were coached on how to use the designed instructional materials while teaching the selected topics. Specifically the activities involved (i) verification of conditions for a substance to float in fluids (ii) relating up thrust and weight a floating body (iii) verification of Hooke's law using a rubber band.

$>$ Classroom observation was carried out before coaching so that researchers could check how teachers facilitated students towards activity based learning.

$>\quad$ Likewise, classroom observation after coaching was done to determine how the use of IIM assisted teachers to conduct physics lessons based on activities approach.

$>\quad$ The classroom observation checklist measured the extent to which teachers' classroom presentation reflected a student-centered approach before and after implementation of IIM in conducting practical lessons (reflected in Table 2 and 3). The observation focused on a number of students per group, students' activities in a group, teachers' activities, and equipment given to students, student interaction and attitude of teacher to encourage students.

$>$ Questionnaires were then administered to teachers to find out the perception of designed instructional materials through the approach of improvisation and the way IIM assisted them to conduct practical lessons on selected topics. The focus was on two main topics of physics namely (i) Elasticity (ii) Law of Flotation. 
$>$ Further interviews were carried out to get clarifications on what was observed or reported in the questionnaires regarding IIM.

The study took place in Tanga region, specifically Tanga urban and Korogwe districts (rural). Two Community Secondary Schools with limited laboratory resources were selected from each district. Tanga urban schools were labeled as A and B. While schools of Korogwe district were labeled as C and D. Eight physics teachers of certificate of secondary education in the selected schools were involved in the study. The involved teachers provided also their professional and experience support in preparing these instructional materials.

Since classroom observation was performed by two different researchers, validity and inter-rater reliability of the observation items were determined by doing a pilot study in a school different from the sampled ones. Then, based on the pilot data; intra-class correlation coefficient (ICC) was determined using the SPSS 10 program and it was found to be 0.82 . Since this value was above the minimum acceptable value of 0.80 , it means the researchers (raters) considerably shared understanding of the performance and the rating scale (Gwet, 2010). However, the researchers still refined the instrument, discussed and further agreed on the other details of the rating pattern such that ICC value calculated after the study increased to 0.84 .

\section{Results}

\subsection{Approaches used by physics teachers prior to IIM}

Research Question 1: What approaches do physics teachers use to organize and facilitate practical work lessons?

The researchers were interested to investigate the approaches that physics teachers use to organize and facilitate running of physics practical lessons in community secondary schools. All eight ( $\mathrm{n}=8,100 \%)$ teachers interviewed in those Community Secondary Schools commented that most of their teaching and learning is conducted through a teacher-centered approach. One of the subject teachers also said that, sometimes he uses diagrams on manila card to demonstrate physics concepts instead of conducting experiments. On the other hand a teacher from school D said: 'I fail to organize practical lessons to my students because the school has no laboratory resources. I normally explain the concepts and give some notes to students'.

Another teacher from school $\mathrm{C}$ with teaching experience of 8 years lamented that, since he was posted to that school he has neither attended any physics workshop nor seminar to sharpen his professional expertise. The other teacher from the same school emphasized that: 'I have seen many changes in a new physics syllabus (specifically 2007 syllabus) which base on student competences, yet there is no any teachers' orientation with regard to such changes'.

In addition the physics log books indicated that no practical lessons were taught in the previous lessons due to lack of laboratory apparatus as mentioned by one of the interviewed teachers from school A that: 'I did not conduct practical lessons because in our school the students do alternative to practical in their form four national examinations'.

Furthermore the practical manuals, syllabus and other physics text books were very few in those selected CSS. Such that school A and B have at least four copies of practical manual each while in school C and D there were no any copy of practical manual. In the case of textbooks few copies were found in all schools.

\subsection{Teachers' views and opinions regarding the IIM}

Teachers' views and opinions - Regarding the content, organization and method of teaching used during the implementation of the IIM, six out of eight teachers who responded to the questionnaires indicated that practical lessons presented by using IIM were relevant, well explained and understood, and the method used in teaching 
Kira, E., \& Nchunga, A.

practical lessons for selected topics was also suitable for a form III students. They emphasized that, IIM enhanced also their subject matter skills, creativity, knowledge and confidence in conducting practical lessons on the law of flotation and elasticity. Describing how the IIM has been useful in broadening their knowledge on the law of flotation and elasticity, one subject teacher asserted that: '...the materials were very useful in enhancing my subject matter skills and they bring about creativity particularly to our school with limited laboratory resources'.

The teacher's statement implies that the usefulness of IIM viewed in terms of increasing teacher's creativity, subject content and pedagogical skill as well as building confidence in conducting practical lessons on the selected topics. Through evaluation forms teachers also acknowledged that IIM present useful, up-to-date information and content and the learning activities per each stage of the materials were appropriate to the level of the learners.

In addition all eight teachers involved in the study responded that, managing practical lessons using IIM has promoted students' attitudes towards the learning of physics subject. The IIM approach was viewed as good because it is cost less and uses available materials that can be found within the school environment. The responses are summarized in Table 1 below.

\section{Table 1}

Teacher's questionnaire responses on Likert-type scale

\begin{tabular}{|c|c|c|c|c|c|}
\hline \multirow{2}{*}{ Questionnaire's item } & \multicolumn{5}{|c|}{ Teachers' responses } \\
\hline & 1 & 2 & 3 & 4 & 5 \\
\hline The approach encourages conducting lessons in activity bases. & $6(75 \%)$ & $2(25 \%)$ & $0(0 \%)$ & $0(0 \%)$ & $0(0 \%)$ \\
\hline The approach arose the prior-knowledge of learners & $6(75 \%)$ & $2(25 \%)$ & $0(0 \%)$ & $0(0 \%)$ & $0(0 \%)$ \\
\hline $\begin{array}{l}\text { The approach promotes attitudes towards learning physics } \\
\text { subject }\end{array}$ & $8(100 \%)$ & $0(0 \%)$ & $0(0 \%)$ & $0(0 \%)$ & $0(0 \%)$ \\
\hline The approach promotes understanding of physics concepts & $8(100 \%)$ & $0(0 \%)$ & $0(0 \%)$ & $0(0 \%)$ & $0(0 \%)$ \\
\hline
\end{tabular}

On presenting the findings five point Likert scales representing perceptions from "strongly agree" to "strongly disagree" were reduced to three points scale which are agree, undecided and disagree.

Table 1 indicates that, all respondents agreed by $100 \%$ that IIM approach:

$>\quad$ Encouraged involvement of learners into conducting practical lesson activities

$>\quad$ Aroused the prior-knowledge of learners

$>\quad$ Promoted attitudes towards learning physics

$>\quad$ Promoted understanding of physics concepts among students

In order to present how teachers felt on the method/approach used in conducting practical lessons, the other section of the questionnaire required teachers to respond to nine questions asking them to agree or disagree with respect to the item. All teachers $(n=8 ; 100 \%)$ agreed that:

$>\quad$ Planning and conducting practical lessons following IIM approach allows creativity.

$>$ IIM had taught them how to use available local material do design physics practical laboratory resources.

$>\quad$ The approach encourages involvement of learners into conducting practical lessons activities because 
instructional material described and identified clearly the activities of learners as well as teachers responsibilities during class presentation,

$>$ The approach explores prior-knowledge of learners

D Designing practical lessons using IIM, goals and objective of competence based physics syllabus of (2007) are realized

$>$ The approach promotes positive attitudes towards learning physics

$>$ The approach promotes understanding of physics concepts

$>$ The approach encourages connection of practical theory and practice

$>$ The approach should completely replace the traditional model of teaching and learning physics practical lessons.

In another item of the questionnaire teachers were requested to evaluate the coaching session before implementation of IIM to students. All teachers $(\mathrm{n}=8 ; 100 \%)$ responded that the coaching session supported them very much to build confidence in managing practical lessons. They added that, the facilitator was very useful as he had enhanced their subject matter knowledge on the law of flotation and elasticity. Teachers also explained that improvised material had enhanced their pedagogical skill as well as built confidence of teaching physics practical lessons. Apart from IIM to enhance teachers' content and pedagogical skills, one teacher said that: 'from coaching session I learnt something new that means how to use surrounding materials in conducting practical lessons especially in Community Secondary Schools with limited laboratory resources'.

Responding to the item of a questionnaire that requested teachers to give their views about IIM approach towards promoting students' attitude in learning physics subject, all teachers $\mathrm{n}=8(100 \%)$ agreed that the approach promoted students' attitude to learn physics subject. One teacher argued that: ' the IIM is very nice because it is cost less and consists of available local material and on top of that students were more involved in the learning process than other lessons they always do'.

Regarding the use of IIM to improve physics performance of the students all eight teacher ( $\mathrm{n}=8 ; 100 \%)$ agreed that managing practical lessons using IIM approach can improve the students' academic performance of physics subject. They further commented that the practical lessons performed with IIM approach had increased students interests and many of students would opt physics and other science subjects like chemistry and biology if the modes of conducting practical lesson in CSS resemble IIM approach.

Reflecting on adoption of IIM approach to Tanzanian Community Secondary Schools, the researchers explored teachers' views. Responses were that the approach was relevant and provided an alternative way of exposing learners to practical work learning because many of CSS have no laboratory rooms and enough scientific apparatus for experiment.

Two of the teachers were of the view that, IIM should be considered by education stakeholder as the way of addressing the challenges of community schools with limited laboratory resources. It should be implemented to all community secondary schools. The other teacher added that there should be a support of seminars and workshop where physics teachers meet and exchange their experiences about running practical lessons through the approach of improvisation.

\subsection{Observations from the Classroom Implementation of IIM}

Observations from the Classroom Implementation of IIM - Twelve class presentations took place in each school (three for every teacher) in which the average score of each participant teacher were combined in two tables which are table 2 before and table 3 after coaching the teachers on the uses of IIM. 
Kira, E., \& Nchunga, A.

Table 2

Summary Score of the Teachers' experiences per Stage before Coaching on the use of IIM

\begin{tabular}{|c|c|c|c|c|c|c|c|c|c|}
\hline \multicolumn{2}{|l|}{ Stages } & T1A & $\mathrm{T} 2 \mathrm{~A}$ & $\mathrm{~T} 1 \mathrm{~B}$ & $\mathrm{~T} 2 \mathrm{~B}$ & $\mathrm{~T} 1 \mathrm{C}$ & $\mathrm{T} 2 \mathrm{C}$ & T1D & $\mathrm{T} 2 \mathrm{D}$ \\
\hline \multirow[t]{2}{*}{ Introduction } & $\mathrm{Obs}_{1}$ & 2 & 2 & 1 & 2 & 2 & 1 & 2 & 1 \\
\hline & $\mathrm{Obs}_{2}$ & 3 & 2 & 1 & 3 & 2 & 1 & 2 & 1 \\
\hline \multirow[t]{2}{*}{ Lesson development } & $\mathrm{Obs}_{1}$ & 1 & 2 & 2 & 2 & 2 & 2 & 2 & 3 \\
\hline & $\mathrm{Obs}_{2}$ & 2 & 2 & 2 & 2 & 2 & 2 & 1 & 3 \\
\hline \multirow[t]{2}{*}{ Class discussion } & $\mathrm{Obs}_{1}$ & 2 & 2 & 2 & 2 & 1 & 2 & 2 & 3 \\
\hline & $\mathrm{Obs}_{2}$ & 2 & 2 & 2 & 2 & 1 & 2 & 2 & 2 \\
\hline \multirow[t]{2}{*}{ Conclusion \& evaluation } & $\mathrm{Obs}_{1}$ & 2 & 2 & 2 & 2 & 2 & 2 & 2 & 2 \\
\hline & $\mathrm{Obs}_{2}$ & 2 & 2 & 2 & 2 & 2 & 2 & 2 & 2 \\
\hline Average score & & 2.00 & 2.00 & 1.75 & 2.13 & 1.75 & 1.75 & 1.88 & 2.13 \\
\hline
\end{tabular}

Source. Field data 2015

Note. (i) TA, TB, TC, and TD means teacher in school A to school D where numbers 1 and 2 represent the 1 st and 2 nd teacher in every school

(ii) Obs1 and Obs2 means class observer 1 and 2, respectively.

(iii) Where 4 = well done, $3=$ satisfactory, $2=$ partially, $1=$ not done at all

\section{Table 3}

Summary Score of the Teachers' experience per Stage after Coaching the Use of IIM to Conduct Practical Lessons

\begin{tabular}{lccccccccc}
\hline \multicolumn{1}{c}{ Lesson Presentation } & Stages & T1A & T2A & T1B & T2B & T1C & T2C & T1D & T2D \\
\hline \multirow{2}{*}{ Introduction } & $\mathrm{Obs}_{1}$ & 3 & 4 & 4 & 3 & 4 & 3 & 3 & 3 \\
& $\mathrm{Obs}_{2}$ & 3 & 4 & 3 & 3 & 3 & 3 & 3 & 3 \\
\multirow{2}{*}{ Lesson development } & $\mathrm{Obs}_{1}$ & 4 & 3 & 4 & 4 & 3 & 3 & 4 & 4 \\
& $\mathrm{Obs}_{2}$ & 4 & 3 & 4 & 4 & 4 & 3 & 3 & 3 \\
Class discussion & $\mathrm{Obs}_{1}$ & 4 & 4 & 4 & 4 & 3 & 4 & 4 & 4 \\
\multirow{3}{*}{ Conclusion } & $\mathrm{Obs}_{2}$ & 3 & 4 & 3 & 4 & 3 & 4 & 4 & 4 \\
evaluation & $\& \mathrm{Obs}_{1}$ & 4 & 3 & 4 & 4 & 4 & 3 & 4 & 4 \\
Average score & $\mathrm{Obs}_{2}$ & 4 & 3 & 4 & 4 & 4 & 3 & 4 & 4 \\
\hline Source. Field data 2015 & & 3.63 & 3.50 & 3.75 & 3.75 & 3.50 & 3.25 & 3.63 & 3.63 \\
\hline
\end{tabular}

Source. Field data 2015

Note. (i) TA, TB, TC, and TD means teacher in school A, B, C, and $\mathrm{D}$, respectively.

(ii) Obs1 and Obs2 means class observer 1 and 2, respectively.

(iii) Where $4=$ well done, $3=$ satisfactory, $2=$ partially, $1=$ not done at all

The analysis from classroom observation sheet (Table 3) indicated that, almost all teachers scored 'partially' or 'not at all' in their classroom presentation except in some minor cases in school B and D who scored a bit higher (2.13) than the other six teachers because of their over ten year experience in teaching. The scores of two teachers from school B (T1B) and C (T2C) is almost the same (1.75). These two teachers were just posted to their respective schools closer to the time of conducting this study. But one cannot conclude that experience for this case matters because teacher $\mathrm{T} 1 \mathrm{C}$ in school $\mathrm{C}$ has scored the same though his teaching experience is over ten years. The observation also reveals that teachers' classroom presentation scores do not depend on school location as teachers from school C and D are from rural areas whereas school A and B are from urban location.

The analysis of classroom observation sheet after coaching the teachers on IIM (Table 3 above) reveals that all eight teachers presented their practical lessons satisfactory in all stages. The stage of introducing the lesson involved activities like students' group formulation, short discussion about experiments followed by rising prior knowledge toward the practical lesson at hand. The lesson development stage comprised activity-based learning, subject matter knowledge and expansion of knowledge as shown in Table 4. For all teachers there was a considerable change in the average scores before and after coaching. 
Table 4

Practical Lesson Execution Procedure during IIM

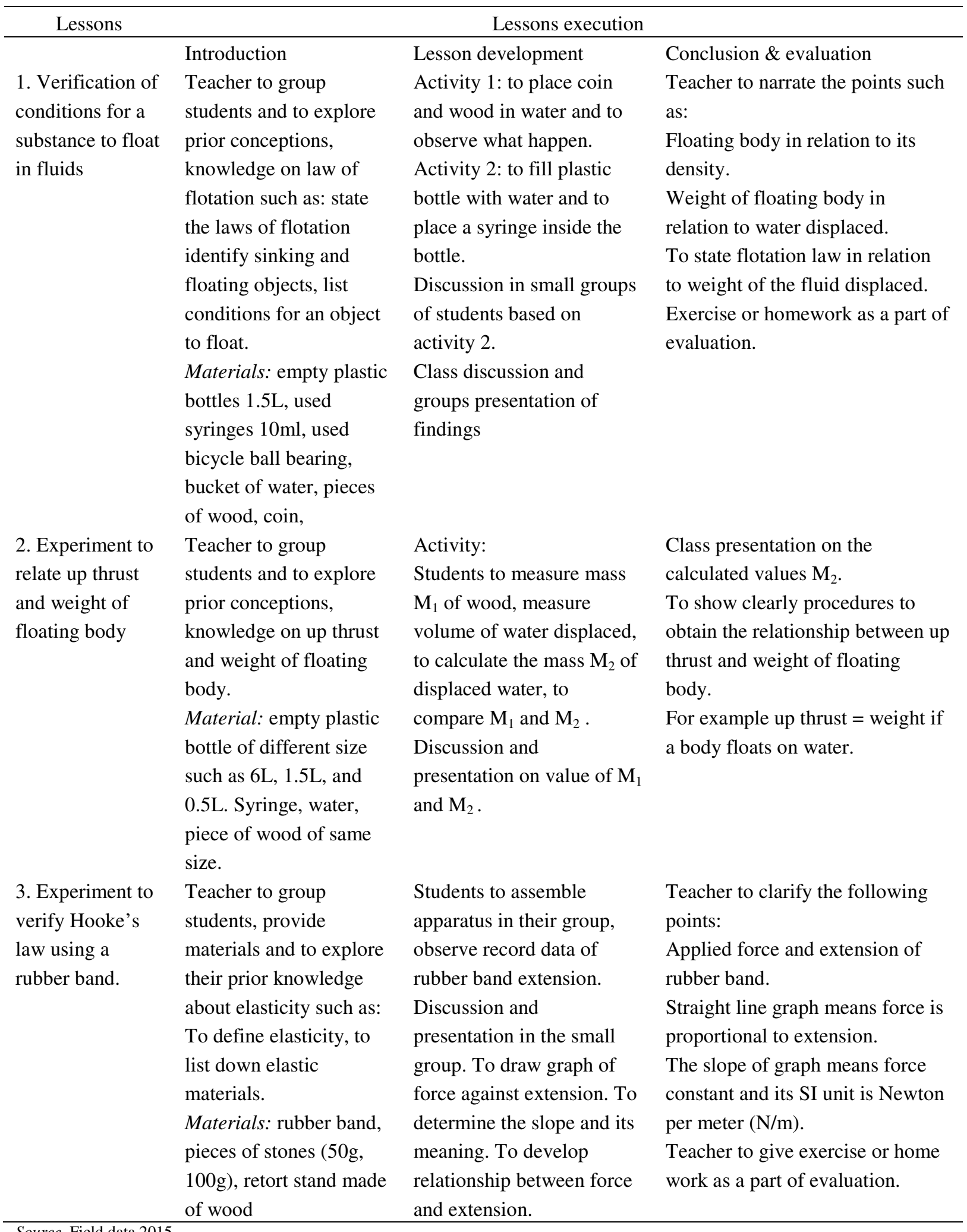

Source. Field data 2015

\subsection{How do Teachers Perceive IIM in Teaching Practical Lessons: Interview Responses}

The researchers intended to explore further through interview whether or not there things noted by teachers 
which differentiated practical lessons supported with IIM from regular lessons. In this regard of the practical lessons they had conducted with IIM, all $n=8(100 \%)$ of teachers interview responses could be summarized as follows:

$>$ IIM coaching increased teacher's confidence in conducting practical lessons.

$>$ Enhancing teacher's subject matter knowledge and skills in conducting practical lessons.

$>\quad$ IIM uses cheap and available materials that can be found around the school environment to serve the purpose and learning objectives stated in the syllabus such as students to have opportunity to perform experiments so as to link theory and practice.

$>$ IIM approach arose the interest and understanding of students towards physics subject

$>\quad$ IIM approach has improved the practical skill of their students on the selected topic, since they were able to draw graph of force against extension of a rubber band and to determine its slope as well as SI units, and to state both Flotation law and Hooke's law correctly.

Basing on the features of the instructional materials all teachers described their perception in terms of their organization, content and method/approach used. In case of organization of the material the teachers acknowledged that it was organized well. They narrated that lessons descriptions in each stage enable them as well as their students to conduct practical lessons as it was supposed to be done. The main IIM organization features were lesson description, specific objectives to be achieved, reference books, list of activities and material in each stage of the experiment, suggested time, suggestions for exercise or home work.

Teachers also indicated in the evaluation forms that the lesson contents were relevant to the level of the students. They emphasized particular relevancy in the way practical lessons were conducted using local materials that are connected to students' life situations such as sinking of pins and floating of plastic bottle in water. The teachers indicated that the method applied to conduct practical lessons was suitable for the class level of students. They added that different from the other lessons based on lecture approach, the practical lessons supported by IIM enabled students to perform most of their lesson activities by themselves.

Moreover teachers said IIM had necessary information on how to facilitate physics practical learning such us how to guide student in group formulation, how to design local laboratory materials, how to use local material to conduct experiments, how to guide students in predictions of experiment results, draw graph, presentation as well discussion of findings. Furthermore, teachers emphasized that information provided in the lessons notes facilitated them to clarify some concepts which were found difficult to some students.

\section{Discussion}

Some scholars think that the importance of traditional laboratory teaching involving practical experimentation and hands on work has in no way decreased as a result of computerized simulation (Crispen et al., 2010). But the findings of this study indicated that modern laboratory resources are still very limited in the surveyed Community Secondary Schools in Tanzania. The physics teaching and learning are mainly conducted through lecture methods whereby students are rarely participated in the whole process of learning. The lecture method promotes teachers to be a centre of knowledge and students act as a passive recipient of knowledge. This implies that considering the abstract nature of physics rarely students understand the concepts without using instructional materials (Aina, 2013) as research shows that teaching of most of the physics concepts by students-cantered techniques is only effective if instructional materials are used (Olufunke, 2012). This could be verified through classroom observations which indicated that before implementation of IIM approach all teachers showed relatively low classroom presentation skills.

This does not necessarily mean that teachers are completely unaware about improvisation as research shows 
that teachers may be aware of the significance of students centered approaches and the use of instructional materials but may not guarantee that they will use them because of several reasons; one of them being time constrain (Jegede \& Adedayo, 2013). This is reason why the main philosophy of IIM was to encourage teachers to improvise local laboratory resources and use them to run practical lessons. Also, research supports that practical lesson teaching requires well motivated, skilled and confident science teachers (Lazarowitz \& Tamir, 1994). Since it was found that all eight teachers accepted that the material had added value in terms of their content and pedagogical skills, creativity and confidence in teaching practical lessons. This means the content, organization and methods of IIM were relevant, and understood to teachers who used them in conducting practical lessons.

Also, the researchers could associate the improvement of teachers' presentation of practical lessons with the coaching (workshop) conducted before the implementation of IIM. The researchers discovered that the workshop about the use of IIM approach to teachers served a purpose of teacher professional development. In the light of teacher professional development; Komba, Nkumbi, and Warioba (2007) argues that, it provides opportunities for teachers to explore new roles, develop new instructional techniques, refine their practice and broaden themselves as educators and as individuals. The researcher further realized that, the use of IIM approach in conducting physics practical lessons refined and broadened teachers' knowledge of using local and cheaply available local materials.

Therefore in the mushrooming community secondary schools in Tanzania, physics teachers have opportunities of utilizing the environment within their school premises to design their own teaching and learning resources. However, since this study has limited itself to some concepts found in two of the topics found in physics, similar studies are essential for orienting physics teachers to a broader scenario of improvisation so that the rest of the concepts in physics can effectively be taught by utilizing our local environment.

\section{Conclusion}

Based on the findings of this study it was revealed that content, organization and methods of teaching using IIM approach seem to be relevant to the teachers' environment and context. IIM approach has been viewed as one of the ways to increase teacher's creativity, subject and pedagogical content skills for teaching physics practical work in the Community Secondary Schools that are extremely limited with teaching and learning resources. The findings also suggest that IIM approach used the mode of teaching in which students are fully involved in all stages of lesson presentation. This means teachers are ready to learn and practice IIM if such materials are well prepared and planned. But since awareness alone is not sufficient condition for teachers to practice preparation and use of such materials they need to be supported through organized teacher professional development programs.

\section{References}

Adedayo, J. O. (2010). Effect of teacher's qualification on the performance of senior secondary school students in Physics: Implication on technology. Paper presented at the 6th annual conference of the Nigerian Educational Research Association University of Nigeria, Nsukka.

Adeyemo, S. A (2011). The effect of teachers' perception and students' perception of physics classroom learning environment on their academic achievement in senior secondary schools physics. International Journal of Educational Research and Technology, 2(1), 74 - 81.

Aina, K. J. (2013). Instructional materials and improvisation in physics class: implications for teaching and learning. Journal of Research \& Method in Education, 2(5), 38-42.

Akanbi, A. O. (2003). An investigation into students' performance in senior secondary school physics. Journal of Teacher Education Trends, 1(1), 58-64 .

Balogun, T. A. (1985). Interest in science technology education in Nigeria. Journal of Teachers Association of Nigeria, 23 (1\&2), 92-99. 
Kira, E., \& Nchunga, A.

Biggs, J. (1999). Teaching for quality learning at university. Suffolk: St. Edmundsbury Press.

Bryman, A. (2001). Social research methods. New York: Oxford University Press Inc.

Chinyere, A. P. (2014). Physics teachers' perception of effective teaching/learning of physics in senior secondary school for global competitiveness. Journal of Research \& Method in Education, 4(1) 20-24.

Chonjo, P., Osaki, K. M., Possi, M. K., \& Mrutu, S.(1996). Improving science education in secondary schools: A Situation analysis of selected government secondary schools in Tanzania mainland. Dar es Salaam: DUP.

Crispen, B., Kusure, L., Munodawafa, V., Sana, A., \& Gwizangwe, I. (2010). Pre-service teachers' use of improvised and virtual laboratory experimentation in science teaching. International Journal of Education and Development using Information and Communication Technology, 6(4), 27-38.

Gardner, H. (2012). Commentary. Getting at the heart of the creative experience. Creativity: Insights, directions, and possibilities. Learning Landscapes, 6(1), 45-54.

Groves, F. H., \& Pugh, A. F. (1999). Elementary pre-service teacher perceptions of the greenhouse effect. Journal of Science Education and Technology, 8(1), 75-81. http://dx.doi.org/10.1023/A:1009433705790

Gwet, K. L. (2010). Handbook of inter-rater reliability: The definitive guide to measuring the extent of agreement among raters (2nd ed.). Gaithersburg, MD: Advanced Analytics LLC.

Hong, J., \& Vargas, P. (2016). Science teachers' perception and implementation of inquiry-based reform initiatives in relation to their beliefs and professional identity. International Journal of Research Studies in Education, 5(1), 3-17. http://dx.doi.org/10.5861/ijrse.2015.1092

Isola, O. M. (2010). Effects of standardized and improvised instructional materials students' academic achievements in secondary school physics. Masteral Thesis, University of Ibadan, Ibadan.

Jegede, S. A., \& Adedayo, J. O. (2013). Enriching physics education in Nigeria towards enhancing a sustainable technological development. Greener Journal of Educational Research, 3(2), 80-84.

Jokolo, M. A. (2004). Classroom interaction in advanced level biology lesson. Unpublished Masteral thesis, University of Dar es salaam, Tanzania.

Kira, E., Komba, S., Kafanabo, E., \& Tilya, F. (2013). Teachers' questioning techniques in advanced level chemistry lessons: A Tanzanian perspective. Australian Journal of Teacher Education, 38(12), 66-79. http://dx.doi.org/10.14221/ajte.2013v38n12.7

Kira, E., \& Mahumbwe, N. (2015). Utilization of the internet facility in Dar es salaam secondary schools in tanzania. Global Journal of Advanced Research, 2(9), 1453-1464.

Kola, A. J. (2007). Uses of instructional materials for teaching and learning Physics in Edu and Patigi Local Government Areas, Nigeria. International Journal of Research in Education, 4(1 \&2), 74.

Komba, W., Nkumbi, E., \& Warioba, L. (2007). Capacity of primary school management for professional development in selected primary schools in Tanzania. Retrieved from http://home.hiroshima-u.ac.jp/cice/wp-content/uploads/publications/report2/AA/Kampala_Tanzania.pdf

Lazarowitz, R., \& Tamir, P. (1994). Research on using laboratory instruction in science. In D. L. Gabel (Ed.), Handbook of research teaching and learning (pp.94-130). New York: Macmillan.

Lujara, S. K., Kissaka, M. M., Trojer, L., \& Mvungi, N. H (2006). Introduction of open source e-learning environment and resource: A novel approach for secondary school in Tanzania. In Proceedings of world academy of science: Engineering and technolog (Vol. 20, p. 331).

Lutege, L. B. (2008) Implementation of problem-solving methods in science education in Tanzania: A study of advanced level physics teaching in Dar es Salaam region. Unpublished Masteral thesis, University of Dar es Salaam, Dar es salaam.

Mafumiko, F. M. S. (2008). The potential of chemistry experimentation in enhancing teaching and learning of secondary chemistry experience from Tanzania. NUE Journal of International Education Cooperation, 3, 63-79.

Mills, H. R. (1991). Teaching and training: A handbook for instructors (3rd ed). London: Macmillan Publishers.

Ministry of Education and Vocational Training. (2008). Basic education development. Retrieved from http://www.moevt.ac.tz

MoEC. (2004). Education Sector Development program. Dar es Salaam: MOEC. 
Improvisation in teaching physics concepts: Teachers' experiences and perceptions

MoEVT. (2007). Physics syllabus for ordinary secondary education form I-IV. Dar es Salaam: Tanzania institute of education.

MoEVT. (2009). Form four national examination results. Dar es Salaam: NECTA.

Montebon, D. R. (2016). Shadow education: Effects on students' self-efficacy in science. International Journal of Research Studies in Education, 5(1), 31-40. http://dx.doi.org/10.5861/ijrse.2015.1212

Njoku, Z. C. (2000). Images of females in science: A gender analysis of science and technology activities in Nigeria primary science textbooks. Journals of primary education, 1(1), 3.

Nwagbo, C. (1995). Effect of guided inquiry and expository teaching methods on the achievement in an attitude to Biology of students of different scientific literacy. Retrieved from http://www.pepreal.cl/FIE/pdf/lopbc/nwagbo.pdf

Olufunke, B. T. (2012). Effect of availability and utilization of physics laboratory equipment on students' academic achievement in senior secondary school physics. World Journal of Education, 2(5), 1-7. http://dx.doi.org/10.5430/wje.v2n5p1

Omotayo, K. A. (2009). An investigation into the acquisition of scientific attitude among junior secondary school students. Journal of National Association of Women in Academic, 1(1), 82-89.

Piaget, J. (1985) Equilibrium of cognitive structure. Chicago: University Press.

Tagg, J., \& Barr, R. B. (1995). From teaching to learning-A new paradigm for undergraduate education. Change (November-December), 13-25. Retrieved from http://www.maine.edu/pdf/BarrandTagg.pdf

URT. (2009). Form four national examination results. Dar es Salaam: NECTA.

Vosnadou, S. (1994) Capturing and modeling the process of conceptual change. In L. A. Hirschfed \& S. A. Gelman (Eds.), Learning and the mind. Domain specificity in cognition and culture (pp. 169-200). New York: Cambridge University Press. http://dx.doi.org/10.1016/0959-4752(94)90018-3

Wilson, J. M., \& Redish, E. F. (1989). Using computer in teaching physics. Physics Today, 34-41. http://dx.doi.org/10.1063/1.881202

Zacharia, Z. C. (2007). Comparing and combining real and virtual experimentation: An effort to enhance students' conceptual understanding of electric circuits. Journal of Computer Assisted Learning, 23(2), 120-132. http://dx.doi.org/10.1111/j.1365-2729.2006.00215.x 
Kira, E., \& Nchunga, A. 